\title{
Métodos genéticos para la reintroducción de monos de los géneros Saguinus, Aotus y Cebus (Primates: Cebidae) decomisados en Bogotá, Colombia
}

\author{
Manuel Ruiz-García ${ }^{1}$, Norberto Leguizamón ${ }^{2}$, Catalina Vásquez ${ }^{1}$, Karen Rodríguez ${ }^{1} \&$ María \\ Ignacia Castillo ${ }^{1}$ \\ 1. Grupo de Genética de Poblaciones Molecular-Biología Evolutiva, Unidad de Genética, Departamento de Biología, \\ Facultad de Ciencias, Pontificia Universidad Javeriana, Cra $7^{\mathrm{a}}$ No 43-82. Bogotá DC, Colombia; \\ mruiz@javeriana.edu.co,mruizgar@yahoo.es \\ 2. Secretaría Distrital Ambiental (SDA), Bogotá, DC, Colombia.
}

Recibido 16-VIII-2009. Corregido 19-I-2010. Aceptado 22-II-2010.

\begin{abstract}
Genetic methods for the reintroduction of primates Saguinus, Aotus and Cebus (Primates: Cebidae) seized in Bogota, Colombia. Primates are one of more confiscated taxa by the environmental authorities in Bogota, Colombia. During 2008, 133 monkeys were confiscated; samples from 115 of them were sequenced by the mitochondrial cythocrome oxidase II gene (mtCOII) and 112 sequences obtained were of high quality. These sequences were compared with those obtained by our research group from individuals directly sampled in the field, with precise geographic origin. So, a more specific geographic area of the Colombian territory could be considered for a correct rehabilitation treatment during the reintroduction of these confiscated animals. The main results with five primate species were: 1- For all the specimens analyzed of Saguinus leucopus, they could be liberated in any geographical area of its distribution range, since only one gene pool was found. 2- For the 14 Aotus sp. individuals sequenced from the SDA (Environmental District Secretariat), one of them (A. vociferans) was coming from the Amazon, seven exemplars belonged to A. griseimembra from the Magdalena Valley and the Colombian Caribbean coasts, four individuals represented to A. brumbacki from the Colombian Eastern Llanos, and two were associated to A. azarae azarae from Northern Argentina and Paraguay (which means that illegal traffic of animals is arriving to Colombia from other South-American countries). 3Out 14 Cebus albifrons sequenced, two belonged to the geographical area of C. a. versicolor, one to C. a. pleei, 10 to $C$. a. leucocephalus and one could be not assigned because its sequence yielded a great genetic divergence with respect to the other specimens sequenced of this species. 4- The two Cebus capucinus sequenced showed to be associated to a gene pool found in the Northern of Chocó, Sucre and Córdoba Departments. 5- Out 11 Cebus apella sequenced, 10 showed to belong to the gene pool presented in the Colombian Eastern Llanos and highly related (but differentiable) to Cebus apella apella from the French Guyana. It could be named C. a. fatuellus sensu Groves (2001). One exemplar sequenced could be not related with the other $C$. apella analyzed, nor the related taxa to the aforementioned species $($ C. a. paraguayanus $=C$. cay; C. xanthosternos; $C$. nigritus $)$. Rev. Biol. Trop. 58 (3): 1049-1067. Epub 2010 September 01.
\end{abstract}

Key words: Population genetics, molecular markers, neotropical primates, liberation of confiscated fauna, Saguinus leucopus, Aotus sp, Cebus albifrons, Cebus capucinus, Cebus apella.

En un país, con la megadiversidad que posee Colombia, es fácil comprender que el tráfico ilegal de fauna sea un problema frecuente. De los 45 millones de habitantes que habitan Colombia, aproximadamente unos siete millones se encuentran en la capital. Esto significa que una fracción considerable de la fauna ilegalmente traficada en este país, en algún momento transitará por la capital colombiana. La Secretaría Distrital Ambiental (SDA) es la institución encargada de recibir, mantener, rehabilitar y reintroducir, cuando es posible, esa fauna ilegal decomisada por las autoridades pertinentes. Buena parte de esa fauna 
decomisada se obtiene en el Terminal de transporte terrestre y en el Aeropuerto de El Dorado, Bogotá. Una fracción de la fauna decomisada está compuesta por mamíferos, siendo los roedores (sciuromorfos-ardillas-, especialmente) y los primates, los taxones más representados. Uno de los problemas más acuciantes, es la reintroducción de esos ejemplares a su ambiente original. No existe una infraestructura física ni un presupuesto económico para mantener en cautiverio toda esa fauna procedente del tráfico ilegal. Sin embargo, es necesario poder rehabilitar a los ejemplares decomisados para devolverlos al medio natural del que proceden. Una problemática es que los datos geográficos, acerca del origen de los ejemplares interceptados, se desconoce ya sea porque los propietarios de esos animales realmente lo ignoran (han pasado por múltiples manos intermedias), o porque ofrecen una información confusa, o falsa, para no delatar a los traficantes originales o los lugares primarios de extracción de esa fauna decomisada. Colombia se caracteriza por contar con múltiples eco-regiones con características ambientales muy diferenciadas (desde una perspectiva macrogeográfica: Caribe, Chocó-Pacífico, cordilleras andinas, llanos Orientales-Orinoquía y Amazonía), y muchos taxones poseen poblaciones en varias de esas macro-regiones ecológicamente bien diferenciadas. Templeton $(1986,1989)$ mostró que si existen poblaciones con rasgos particulares, o características genéticas exclusivas, y si estas poblaciones no son particularmente pequeñas en sus números efectivos, entonces, resulta vital la conservación de la historia filogenética distintiva y las co-adaptaciones correspondientes de cada una de las poblaciones implicadas. Este autor también señaló que se deben evitar pérdidas, por hibridación, de adaptaciones específicas a ambientes exclusivos debido a que la presencia de depresión exogámica destruye complejos genéticos perfectamente co-adaptados a las características singulares de esos ambientes referidos. Por lo tanto, los animales previamente rehabilitados deben ser liberados en las zonas geográficas de las cuáles fueron ilegalmente extraídos. Por ejemplo,
Girman et al. (1995) mostraron la existencia de tres poblaciones fundamentales del amenazado perro salvaje africano, o licaón, (Lycaon pic$t u s)$. Dos de ellas han sufrido un notable decrecimiento en los dos últimos siglos, la del este y la del oeste africano. La mayor parte de los animales en cautiverio proceden de la población de África del Sur. En un primer momento, se propuso utilizar los ejemplares más numerosos procedentes de África del Sur mezclándolos con los escasos ejemplares del África Oriental. Sin embargo, con la utilización de RFLP (Restriction Fragment Length Polymorphism) aplicados al ADN mitocondrial, se observó más de un uno por ciento de divergencia nucleotídica promedio y la formación de dos clados monofiléticos, conteniendo cada uno de ellos tres haplotipos diferentes. Se determinó, siguiendo los requisitos expuestos por Avise \& Ball (1990), que ambos linajes representaban dos subespecies diferentes y, por lo tanto, se desestimaron los cruzamientos entre ejemplares sudafricanos y del África oriental.

Otra consideración importante es que si se dan cruzamientos entre ejemplares de diferentes acervos genéticos es posible que en las primeras generaciones se de algún tipo de heterosis positiva para caracteres cuantitativos (por ejemplo, aumento de tamaño corporal) pero, posteriormente, se ha detectado un claro descenso en la adaptabilidad de los descendientes (Lynch 1991).

La determinación de qué especies y taxones de primates existe en Colombia es compleja. No existe un consenso claro por parte de los autores, debido a la cambiante sistemática y compleja taxonomía de los primates neotropicales. Por ejemplo, Rylands et al. (1997) determinaron 31 especies y 51 taxones de primates en Colombia, con cuatro especies y 18 taxones endémicos. Russell A. Mittermeier, en el prólogo del libro de Defler (2003), cita la existencia de 27 especies y 43 taxones de primates en Colombia, mientras que Defler (2003), en el mismo libro, comenta la posible existencia entre 26 y 32 especies de primates. Actualmente se sabe que Colombia ocupa la segunda posición (junto con Perú) con respecto 
al número de diferentes taxones de Primates en Latinoamérica (después de Brasil) y la sexta o séptima posición mundial en número de especies, después de Brasil, Zaire, Camerún, Indonesia y Madagascar.

Por ese motivo, se inició hace años una intensa cooperación, entre la SDA y el laboratorio de Genética de Poblaciones Molecular-Biología Evolutiva del Departamento de Biología de la Pontificia Universidad Javeriana en Bogotá, para intentar determinar el posible origen geográfico de una buena parte de los primates decomisados en Bogotá y poder proceder a su liberación en regiones geográficas correctas. Este es un laboratorio que, desde 1996, empezó a recolectar y analizar, con procedimientos genético moleculares, muestras de mamíferos neotropicales de un considerable número de especies (carnívoros-incluyendo félidos, úrsidos, cánidos, prociónidos y mustélidos-, cérvidos, tayasuidos, tapíridos, delfines de río y mamíferos marinos, algunos roedores, perezosos, armadillos, osos hormigueros y primates, con especial énfasis en los géneros Alouatta, Ateles, Lagothrix, Pithecia, Cacajao, Callicebus, Cebus, Saimiri, Aotus, Saguinus, Callithrix y Cebuella).

Para determinar aspectos filogenéticos y filogeográficos con primates neotropicales se utilizaron las secuencias del gen mitocondrial citocromo oxidasa II (mtCOII). Se secuenciaron aproximadamente entre 600 y 730 pares de bases (pb) dependiendo de las especies de primates consideradas. Este gen mitocondrial se ha utilizado de forma exitosa para determinar la filogenia molecular de diversos primates neotropicales. Estos son los casos de Aotus (Ashley \& Vaughn 1995, Plautz et al. 2009, Ruiz-García et al. 2010a), Alouatta (Figueiredo et al. 1998, Cortés-Ortiz et al. 2003, RuizGarcía et al. 2010b), Ateles (Collins \& Dubach 2000a,b, Nieves et al. 2005, Ruiz-García et al. 2010c), Cebus apella (Ruiz-García \& Castillo 2010), Cebus capucinus (Ruiz-García et al. 2010d), Cebus albifrons (Ruiz-García et al. 2010e), Lagothrix (Ruiz-García \& Pinedo 2010a,b,c) y Saguinus leucopus (Ruiz-García et al. 2010f) y otros calitrícidos (Ascunce et al. 2002, Sena et al. 2002).

No obstante, este gen, como otros genes mitocondriales, puede presentar ciertos problemas para la resolución de la filogenia de los primates, tales como la heterogeneidad en la composición de bases en cada posición codónica, diversas tasas de substitución respecto a transiciones y transversiones, y saturación, por evolución muy rápida, de la tercera posición nucleotídica en los codones. Sin embargo, Ascunce et al. (2003) demostraron que en estudios a nivel intra-específico o intra-genérico, las secuencias de este gen son informativas desde la perspectiva filogenética, aunque no para la resolución conjunta de todos los géneros de primates neotropicales.

Por lo tanto, aprovechando el conocimiento adquirido en la filogeografía molecular de los géneros y especies de primates referidos anteriormente, se procedió a analizar los primates recibidos por la SDA en el año 2008, para proponer las áreas geográficas idóneas para la liberación de ejemplares decomisados, mediante la secuenciación del gen mtCOII y la comparación con los primates analizados previamente y que cuentan con un origen geográfico preciso.

\section{MATERIALES Y MÉTODOS}

Una vez que los animales decomisados llegaron a las instalaciones de la SDA, procedentes del Aeropuerto Internacional El Dorado o del terminal de transporte terrestre de Bogotá, los animales fueron objeto de un reconocimiento veterinario para determinar su estado de salud. Los animales fueron anestesiados y se procedió con la extracción de 1-3ml de sangre para las pruebas médicas correspondientes. Una pequeña fracción de esa sangre se depositó en tubos con EDTA disódico para el análisis genético. Los protocolos seguidos fueron aquellos aceptados por el estado colombiano para el caso de fauna silvestre decomisada. De esos 133 especimenes recuperados, se analizaron, para este trabajo, 115 muestras que corresponden a cinco de los taxones incautados (tres 
especies de Cebus, una especie de Saguinus y diferentes taxones del género Aotus). Tres de esas muestras fallaron en la amplificación quedando, entonces, un total de 112 muestras secuenciadas. Las especies y el número de ejemplares de cada una de ellas se puede observar en el Cuadro 1. Porcentualmente, el 51.13\% de los primates decomisados correspondió a Saguinus leucopus, el $12.03 \%$ a Cebus albifrons, el $11.28 \%$ a Aotus sp, el $10.53 \%$ a Saimiri sciureus, el $8.27 \%$ a Cebus apella, el 3\% a Saguinus oedipus, el 1.5\% tanto para Cebus capucinus como para Callicebus cupreus y el $0.75 \%$ a Lagothrix lagotricha. Las especies cuyos individuos pudieron ser analizados, en un primer nivel de ejecución, con secuencias procedentes de ejemplares muestreados en la naturaleza fueron: Saguinus leucopus, Aotus sp., y las tres especies de Cebus. Para S. leucopus, se disponían de 47 secuencias de especimenes con origen geográfico conocido. Para C. albifrons, se contaba con 106 secuencias de orígenes geográficos precisos, representando

CUADRO 1

Composición de especies de primates decomisados por la SDA en 2008. En sombreado gris son las especies analizadas molecularmente con resultados concluyentes en cuanto al lugar geográfico preciso y conveniente para la liberación. En blanco, muestras recibidas pero no analizadas o no incluidas en el presente trabajo.

TABLE 1

Species composition of confiscated primates by the SDA in 2008. In gray shadow, species molecularly analyzed with clear results regarding their right geographic origins for liberation purposes. In white, samples received but not analyzed or not included in the current work.

$\begin{array}{lc}\text { Especie } & \text { No. de individuos } \\ \text { Cebus albifrons } & 16 \\ \text { Saguinus leucopus } & 68 \\ \text { Aotus sp. } & 15 \\ \text { Cebus apella } & 11 \\ \text { Cebus capucinus } & 2 \\ \text { Saguinus oedipus } & 4 \\ \text { Saimiri sciureus } & 14 \\ \text { Lagothrix lagotricha } & 1 \\ \text { Callicebus cupreus } & 2 \\ \text { TOTAL } & 133\end{array}$

10 taxones (subespecies "sensu" Hershkovitz 1949) diferentes de esta especie. Para Aotus, se disponía de 134 secuencias, representando todos los taxones de Aotus reconocidos hasta la fecha. Para $C$. apella, se contó con 34 secuencias representando la mayor parte de los taxones reconocidos en Latinoamérica y con origen geográfico exacto. Finalmente, para C. capucinus se dispusieron 112 secuencias representando todas las poblaciones geográficas reconocidas en Colombia, Costa Rica y Guatemala. También se podría haber asignado geográficamente el ejemplar de Lagothrix lagotricha, ya que se dispone de más de 160 secuencias de este taxón con origen geográfico conocido, pero la extracción de ADN para ese espécimen no fue de adecuada calidad. Los ejemplares de Saimiri decomisados están próximos a ser asignados, pero los resultados no están disponibles para el presente estudio.

Análisis moleculares: La extracción del ADN de las muestras de sangre se realizó empleando el protocolo estándar de fenol-cloroformo (Sambrook et al. 1989). Una vez que se obtuvo el ADN, se realizó PCR (Reacción en Cadena de la Polimerasa) para amplificar la región del gen mtCOII. Para dicha amplificación se obtuvo un volumen final de $50 \mu$, con $5 \mu \mathrm{l}$ de $\mathrm{MgCl}_{2}, 6 \mu \mathrm{l}$ de Buffer 10X, $2 \mu \mathrm{l}$ de dNTP's (4pmol de cada primer), $2 \mu 1$ de ADN (50-100ng por $\mu \mathrm{l}), 2 \mu \mathrm{l}$ de cada uno de los cebadores H7766 (5'-AACCATTTCATAACTTTGTCAA-3') y L6955 (5'-CTCTTAATCTTTAACTTAAAAG-3') (Ashley \& Vaughn 1995) y $2 \mu 1$ de Taq Polimerasa GoTaq (Promega). En el caso de Saguinus leucopus, la secuencia fue de 701 pares de bases (pb), para Aotus sp y Cebus apella fue de 590pb, para $C$. albifrons fue de $696 \mathrm{pb}$ y para $C$. capucinus fue de $710 \mathrm{pb}$. Todas las secuencias fueron obtenidas directamente por los autores y ninguna de ella proviene del GenBank.

Para llevar a cabo la PCR se empleó un termociclador Bio-Rad y las condiciones fueron una denaturación inicial a $95^{\circ} \mathrm{C}$ por $2 \mathrm{~min}$, y de 35 ciclos que constaron de tres pasos: una denaturación a $95^{\circ} \mathrm{C}$ por $45 \mathrm{~s}$, un segundo paso 
de anillamiento a $50^{\circ} \mathrm{C}$ por $30 \mathrm{~s}$ y un tercer paso de extensión a $72^{\circ} \mathrm{C}$ por $35 \mathrm{~s}$. Se llevó a cabo una extensión final a $72^{\circ} \mathrm{C}$ por $5 \mathrm{~min}$.

Para determinar la obtención del amplificado esperado, se llevó a cabo una electroforesis en gel de agarosa al $2 \%$ teñido con bromuro de etidio, visualizándose el posible amplificado en un transiluminador de rayos UV.

Las muestras que amplificaron fueron purificadas mediante columnas de Qiagen. Las secuencias fueron obtenidas mediante un secuenciador automático de ADN 377A (ABI). Las muestras fueron secuenciadas en ambas direcciones y todas las muestras que no presentaron una secuencia limpia fueron secuenciadas hasta dos veces más.

El gen mtCOII es un gen indispensable que juega un papel transcendental en el paso oxidativo terminal del metabolismo energético, debido a que cataliza la transferencia de electrones desde el citocromo c reducido a oxigeno produciendo agua. También es un gen trascendente en la síntesis de ATP en el proceso de la fosforilación oxidativa (Capaldi 1990). En ciertos primates (platirrinos, catarrinos y Hominoidea) se observó el doble de la tasa de substitución aminoacídica que en los prosimios (Adkins \& Honeycutt 1994) y la variación encontrada, tanto en las secuencias nucleotídicas como aminoacídicas, es, en los primates, muy superior a la encontrada en otros mamíferos, como los roedores (Ramharack \& Deeley 1987). Por ejemplo, el terminal carboxílico de la proteína COII es en extremo variable en los primates neotropicales y muestra adiciones y deleciones de aminoácidos respecto a lo encontrado en otros mamíferos (Adkins \& Honeycutt 1994).

Análisis de la Información: Los alineamientos de las secuencias de mtCOII se llevaron a cambio manualmente y con el programa DNA Alignment (Fluxus Technology Ltd). El primer análisis llevado a cabo fue la aplicación del programa FindModel para determinar, entre 28 modelos evolutivos nucleotídicos diferentes, cuál era el más probable. Una vez determinados cuáles fueron los modelos evolutivos óptimos, los mismos fueron incorporados a los siguientes análisis.

Para asignar los ejemplares decomisados, se emplearon diversas metodologías filogenéticas con tasas de transiciones-transversiones que oscilaron entre 5:1 a 15:1 (Ashley \& Vaughn 1995). Se emplearon diferentes métodos de distancias genéticas como la de dos parámetros de Kimura (1980), la de tres parámetros de Tamura (1992) y la del método Log-Det (Nei \& Kumar 2000) mediante dos algoritmos para construir árboles filogenéticos, "neighborjoining” y UPGMA (Saitou \& Nei 1987, Sneath \& Sokal 1973, Tamura et al. 2004). También se emplearon métodos de máxima verosimilitud, de máxima parsimonia y dos procedimientos diferentes con métodos bayesianos (Ronquist \& Huelsenbeck 2003, Drummond \& Rambaut 2007). Los programas empleados fueron Mega 4.1, PAUP*4.0b8, MrBayes v. 3.1 y BEAST v. 1.4.8. Se empleraron 1000 repeticiones "bootstrap" para determinar la robustez de los diversos grupos encontrados, en el caso de los árboles mostrados en este trabajo.

Para la elaboración de los árboles filogenéticos fue necesario contar con uno o varios grupos externos ("outgroups") y de esta manera poder enraizar correctamente los árboles obtenidos. En el caso de las relaciones de Saguinus leucopus se utilizaron muestras de las especies del mismo género, $S$. oedipus (procedentes de Colombia), S. fuscicollis y S. labiatus (ambos procedentes de la Amazonía peruana), de varios taxones de Lagothrix lagotricha (lugens, lagotricha y cana) procedentes de Colombia y Brasil, y de C. albifrons de Colombia. En el caso de Aotus sp. se emplearon muestras de Cebus albifrons, Cebus apella, Ateles paniscus, Ateles chamek y Ateles geoffroyi, procedentes de Colombia, Brasil, Perú y Guatemala. Para los árboles de C. albifrons y C. capucinus, se utilizaron como miembros externos secuencias de Lagothrix lagotricha lugens procedentes de Colombia, mientras que para $C$. apella se utilizó como miembro externo a Aotus azarae boliviensis procedente de Bolivia. Todas esas muestras fueron directamente obtenidas en la naturaleza por el primer autor. Como este 
no es un análisis propiamente filogenético, se muestra solamente un único árbol por especie que presenta, lo más claramente posible, la asignación de los individuos decomisados con muestras procedentes de la naturaleza.

\section{RESULTADOS}

Se presenta el árbol filogenético de los ejemplares decomisados, Saguinus leucopus, Fig. 1, Aotus, Fig. 2; Cebus albifrons, Fig. 3; Cebus capucinus, Fig. 4; Cebus apella, Fig. 5). Para Saguinus leucopus (Fig. 1), el árbol que se presenta es mediante el algoritmo "neighborjoining" con la distancia de tres parámetros de Tamura (1992). Se observó una muy baja diferenciación entre las agrupaciones obtenidas (valores muy bajos del porcentaje de "bootstrap") y muy poca estructuración en las ramas del árbol.

En la asignación de los individuos del género Aotus, se pudo determinar con exactitud a qué taxones pertenecían los individuos decomisados. Para ello se muestra un árbol de máxima parsimonia y 69 ejemplares de Aotus, no se incluyeron todas las secuencias obtenidas previamente para este género en el presente análisis por no ser necesario para ubicar los ejemplares decomisados (Fig. 2). Se determinó un clado de $A$. vociferans $(68 \%$ de "bootstrap"). En el interior de este clado se encontraron cuatro acervos genéticos diferenciados. Se observó que uno los individuos decomisados (SDA16) se agrupó en el tercer subconjunto de A. vociferans ( $32 \%$ de "bootstrap"), siendo esta especie de origen amazónico. Por lo tanto, de los ejemplares decomisados por la SDA, los Aotus procedían de la Amazonía. Se obtuvo otra agrupación que correspondió a la especie A. griseimembra ( $97 \%$ de "bootstrap") de siete individuos. Un tercer ensamble, altamente relacionado con el anterior, correspondió a $A$. brumbacki (99\% de "bootstrap") en el que se agruparon cuatro de los individuos.

Para Cebus albifrons, se muestra el árbol "neighbor-joining" con la distancia de tres parámetros de Tamura (1992) (Fig. 3). Ciertas agrupaciones muestran ser muy sólidas ya que poseen elevados porcentajes de "bootstrap", aunque la relación entre esas agrupaciones principales no resultó bien establecida. En el norte de Colombia aparecen tres clados bien consolidados: uno conformado por $C$. a. versicolor, C. a pleei y C. a. cesarae; otro por $C$. a. leucocephalus, y un tercero por C. a. malitosus. Igualmente, se detectaron cinco acervos genéticos diferentes en los Llanos Orientales y el Amazonas. El Clado I Amazónico estuvo constituido exclusivamente por ejemplares de Vaupés. De este clado parece haber descendido el grupo integrado por versicolor-pleeicesarae. El Clado II podría estar compuesto por varios grupos diferentes, pero estarían básicamente relacionados con C. albifrons albifrons. El Clado III se extendería por la Amazonía brasileña, colombiana y peruana y podría representar C. a. unicolor. El Clado IV estaría conformado por haplotipos dispersos por la Amazonía peruana, colombiana y brasileña y podrían representar C. a. yuracus. Este grupo podría haber generado C. a. leucocephalus de la parte norte de Colombia. El Clado V también se encontraría disperso por diferentes partes de la Amazonia colombiana y peruana y habría dado lugar a C. a. malitosus. Dos individuos decomisados pertenecieron al grupo versicolor, uno al grupo pleei, 10 al grupo de leucocephalus y uno no pudo ser asignado a ninguno de los taxones de C. albifrons analizados, mostrando una secuencia altamente divergente de los restantes $C$. albifrons analizados.

En el caso de Cebus capucinus, se presenta un árbol "neighbor-joining" con la distancia de dos parámetros de Kimura (1980) (Fig. 4). No se incluyeron todas las secuencias disponibles de esta especie ya que no fueron necesarias para la función requerida. Se encontraron cuatro acervos genéticos. Un primer acervo perteneciente a la parte del norte del Chocó, Sucre y Córdoba; un segundo acervo de la zona norte del Magdalena, Antioquia y Cauca; un tercero de Costa Rica y Guatemala; y en cuarto lugar, ciertos haplotipos diferenciados del Cauca. Los dos ejemplares analizados procedentes de la SDA presentaron una fuerte similitud genética 


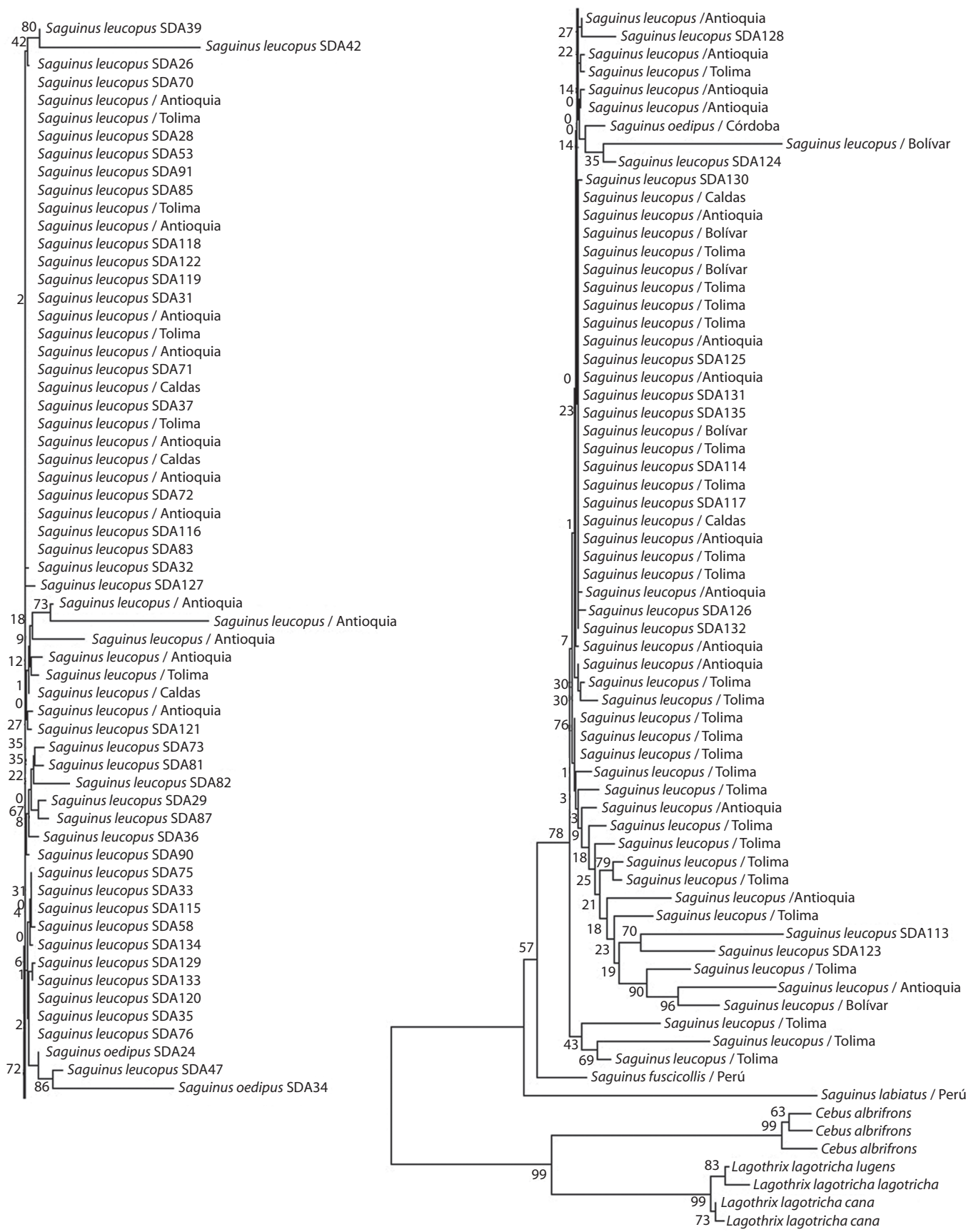

Fig. 1. Árbol "Neighbor-joining" con la distancia de tres parámetros de Tamura (1992) con secuencias de 701 pb del gen mtCOII aplicado al primate neotropical, Saguinus leucopus.

Fig. 1. Neighbor-joining tree with the Tamura (1992)'s three parameter genetic distance with sequences of $701 \mathrm{bp}$ at the mtCOII gene, applied to the neotropical primate, Saguinus leucopus. 


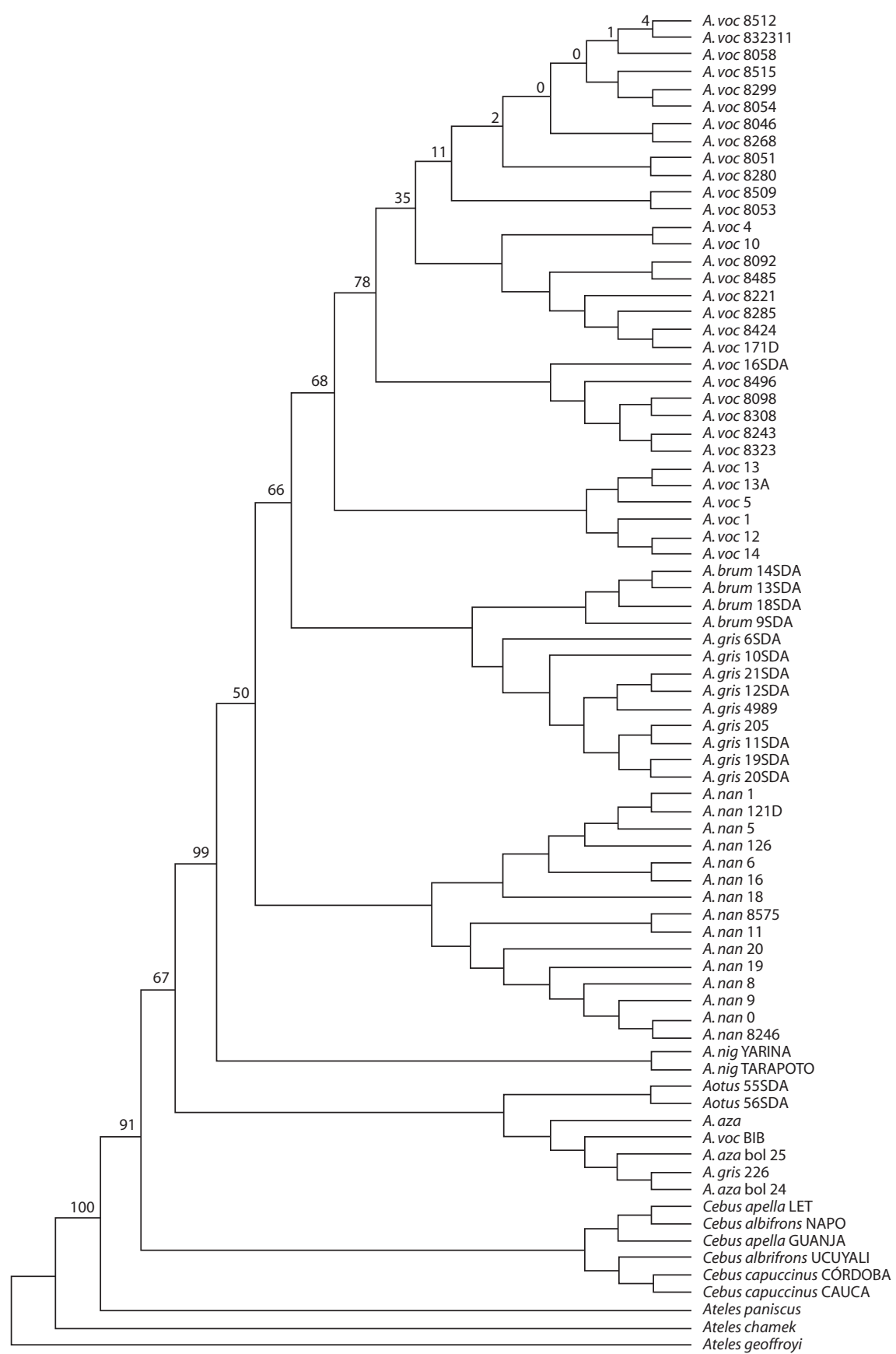

Fig. 2. Árbol de máxima parsimonia con secuencias de 590 pb del gen mtCOII aplicado al género de primate neotropical, Aotus; voc=vociferans; brum=brumbacki; gris=griseimembra; nan=nancymaae; nig=nigriceps; aza=azarae azarae; aza bol=azarae boliviensis.

Fig. 2. Maximum parsimony tree with sequences of $590 \mathrm{bp}$ at the mtCOII gene applied to the neotropical primate genus, Aotus voc=vociferans; brum=brumbacki; gris= griseimembra; nan=nancymaae; nig=nigriceps; aza=azarae azarae; aza bol=azarae boliviensis. 


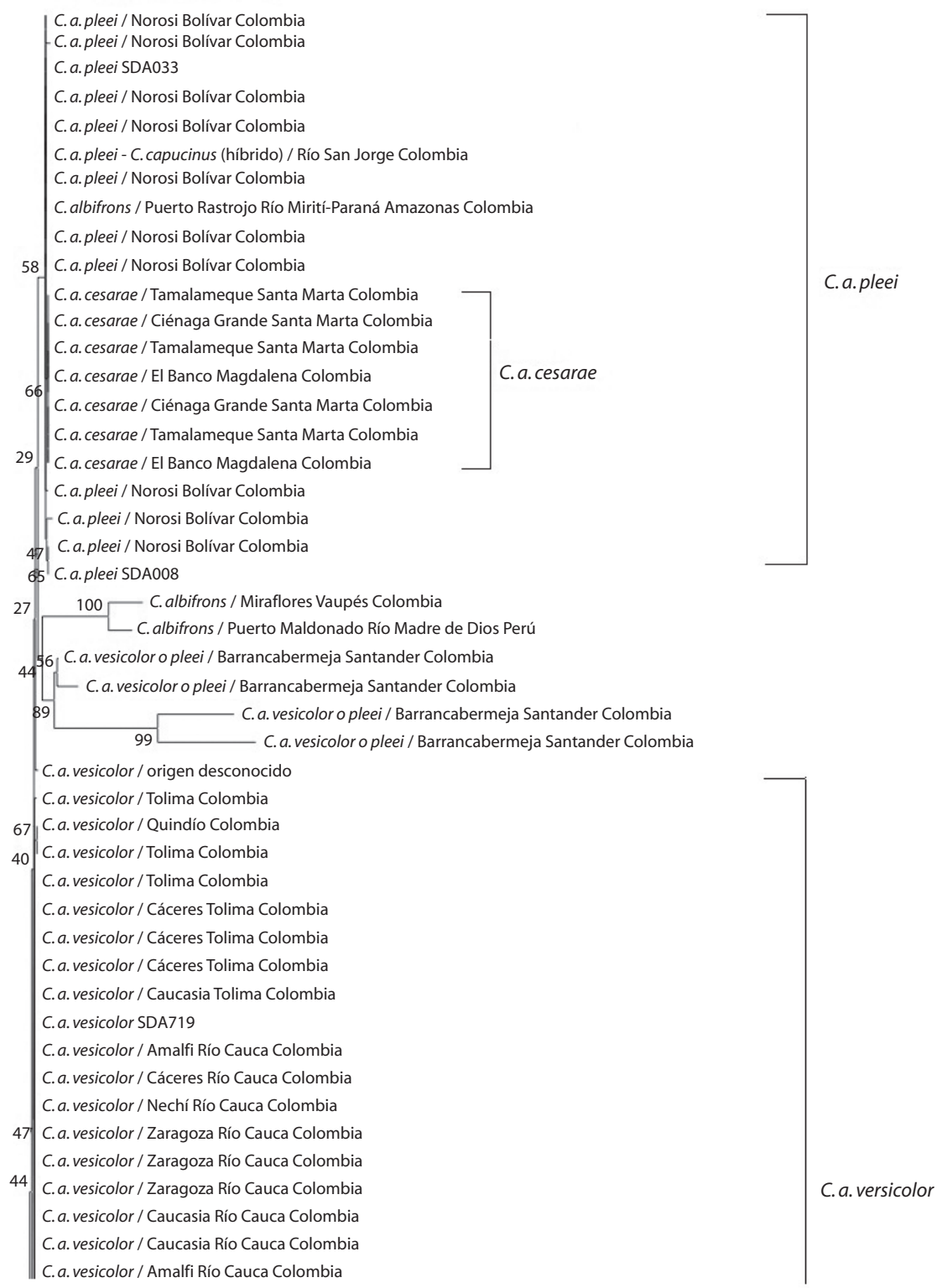

Fig. 3. Árbol "neighbor-joining" con la distancia de tres parámetros de Tamura (1992) con secuencias de 696 pb del gen mtCOII aplicado al primate neotropical, Cebus albifrons.

Fig. 3. Neighbor-joining tree with the Tamura (1992)'s three parameter genetic distance with sequences of 696 bp at the mtCOII gene applied to the neotropical primate, Cebus albifrons. 


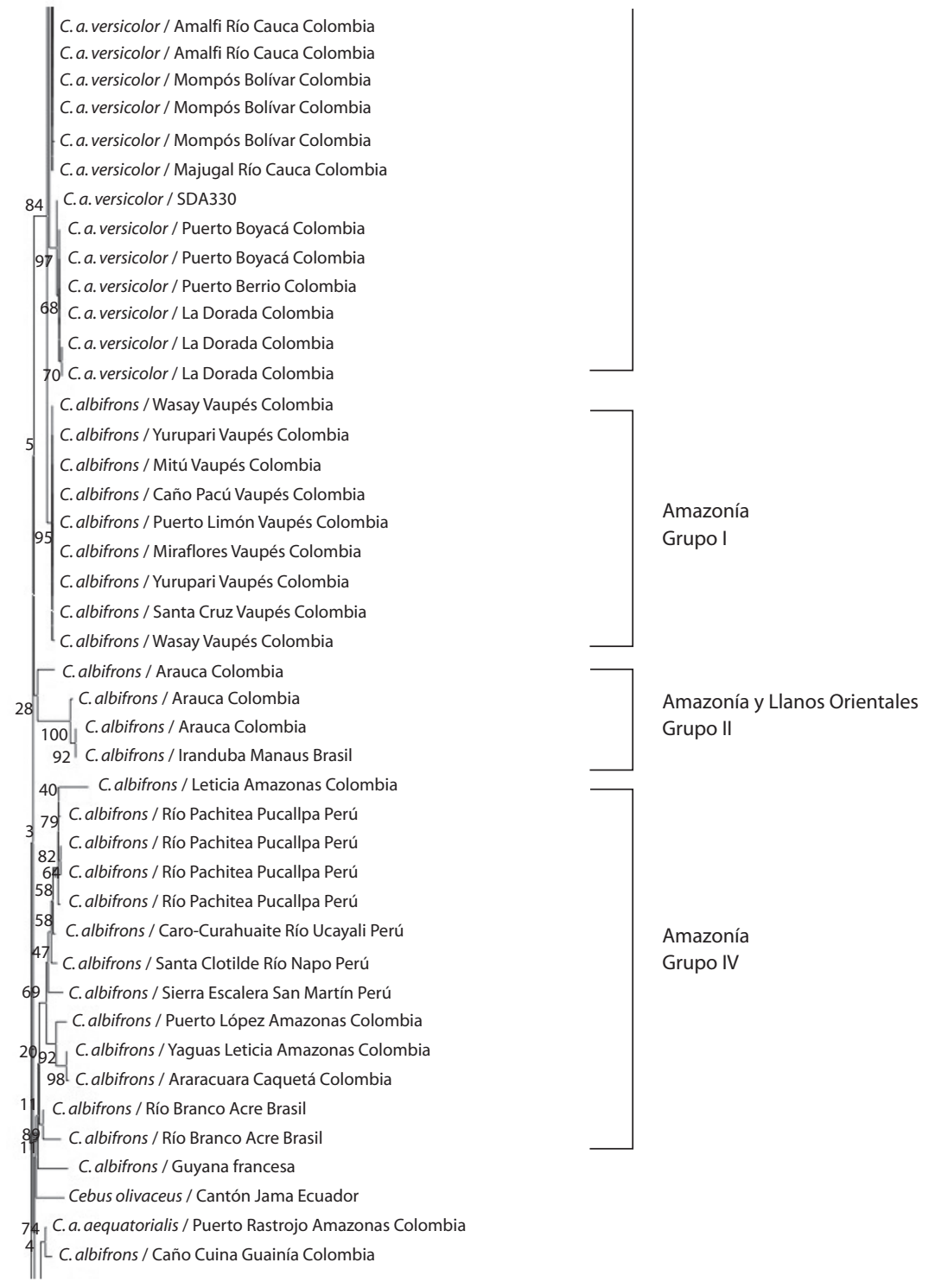

Fig. 3 (Continuación). Árbol "neighbor-joining” con la distancia de tres parámetros de Tamura (1992) con secuencias de 696 pb del gen mtCOII aplicado al primate neotropical, Cebus albifrons.

Fig. 3 (Continued). Neighbor-joining tree with the Tamura (1992)'s three parameter genetic distance with sequences of 696 $\mathrm{bp}$ at the mtCOII gene applied to the neotropical primate, Cebus albifrons. 


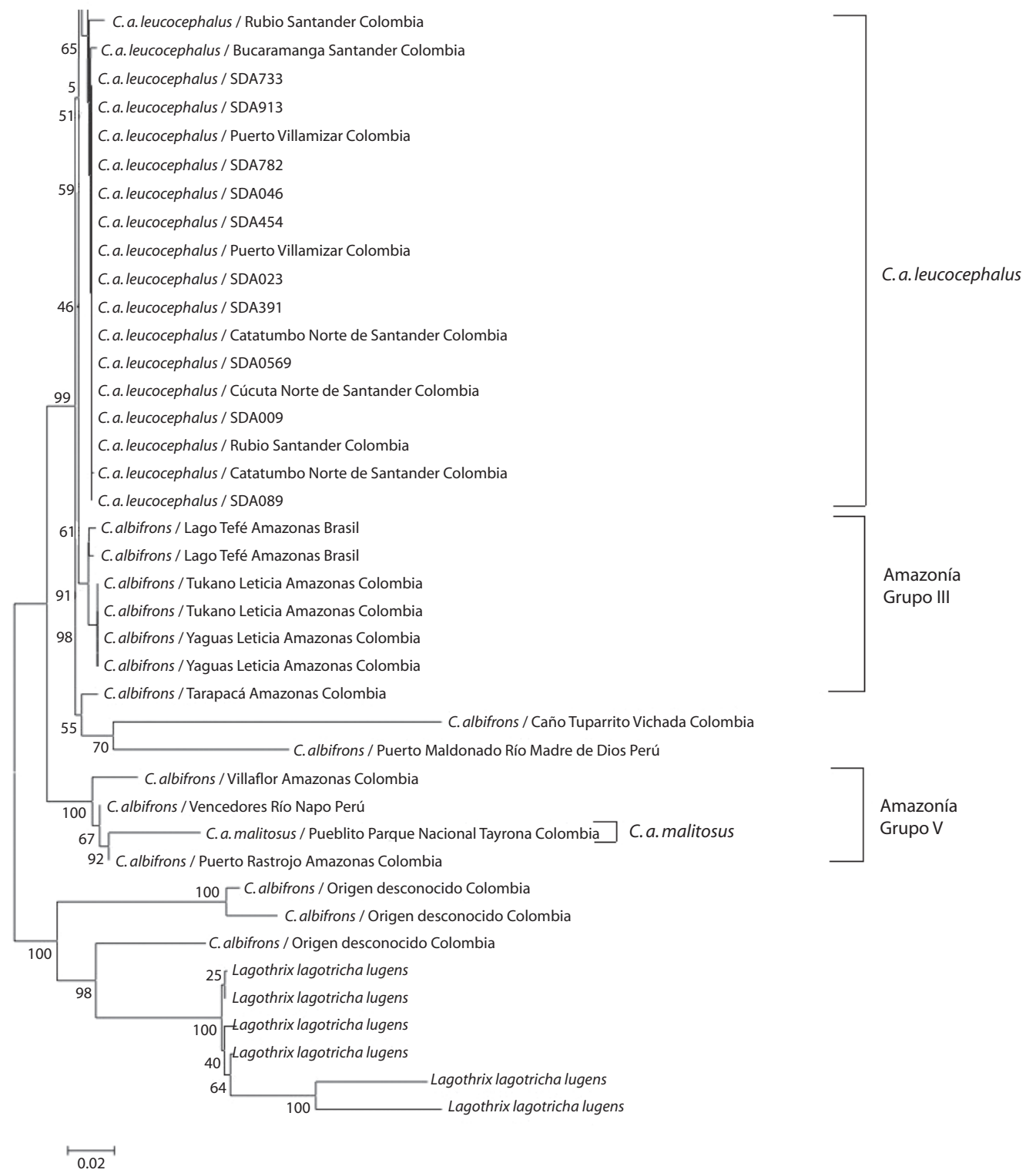

Fig. 3 (Continuación). Árbol "neighbor-joining" con la distancia de tres parámetros de Tamura (1992) con secuencias de 696 $\mathrm{pb}$ del gen mtCOII aplicado al primate neotropical, Cebus albifrons.

Fig. 3 (Continued). Neighbor-joining tree with the Tamura (1992)'s three parameter genetic distance with sequences of 696 bp at the mtCOII gene applied to the neotropical primate, Cebus albifrons. 


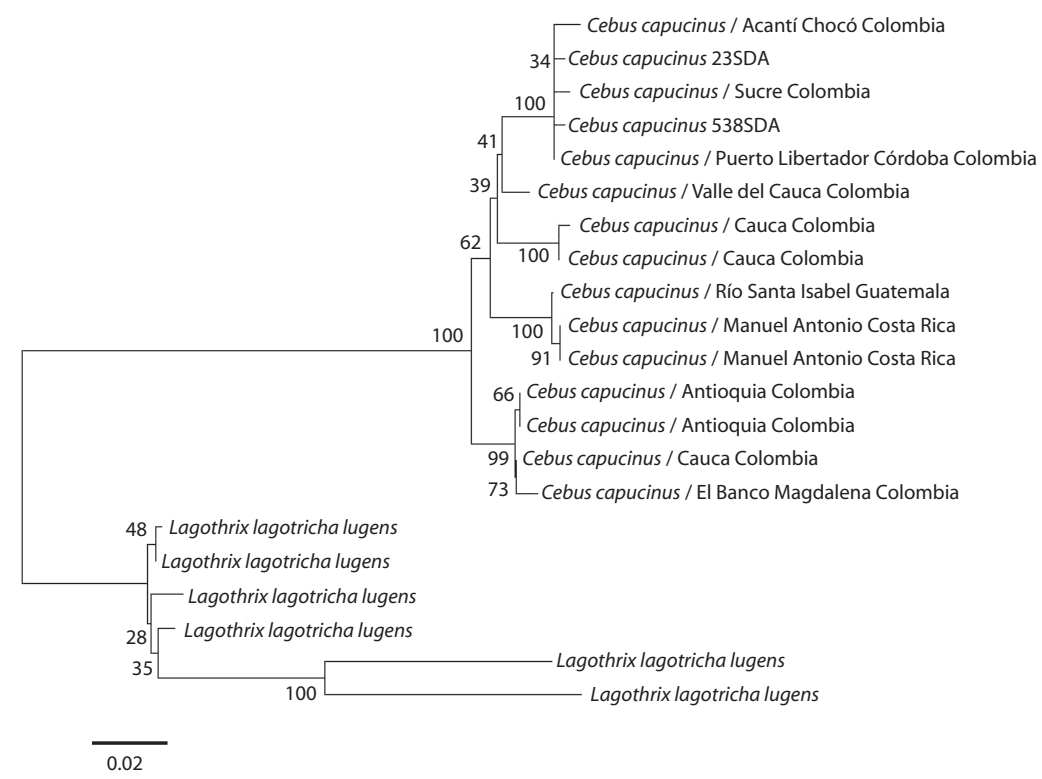

Fig. 4. Árbol "neighbor-joining" con la distancia de dos parámetros de Kimura (1980) con secuencias de 710 pb del gen mtCOII aplicado al primate neotropical, Cebus capucinus.

Fig. 4. Neighbor-joining tree with the Kimura (1980)'s two parameter genetic distance with sequences of 710 bp at the mtCOII gene applied to the neotropical primate, Cebus capucinus.

a los haplotipos del norte del Chocó, Sucre y Córdoba.

En el caso de Cebus apella, se muestra el árbol con el método de máxima parsimonia (Fig. 5). Diez de los once ejemplares procedentes de la SDA mostraron una alta asociación entre sí y estuvieron relacionados con ejemplares procedentes de los Departamentos de Meta, Vichada, Arauca y Guainía. Este grupo, a su vez, estuvo asociado a un clado que contenía cuatro especimenes de $C$. apella de Guyana Francesa y un ejemplar capturado en el norte del río Negro, relativamente cerca de Manaus (Brasil). Por lo tanto, esos ejemplares decomisados provienen de los Llanos Orientales colombianos y deberían ser liberados en esa área de Colombia. El único animal que no quedó englobado en ese grupo (10800080) mostró ser extremadamente divergente y no pudo ser asignado a ninguno de los taxones de Cebus apella, o relacionados con C. ape$l l a$, que se analizaron en el presente trabajo. Ninguno de $\operatorname{los} C$. apella de la SDA tuvo un origen amazónico. En el árbol se observa un gran grupo básicamente amazónico con animales procedentes de diferentes regiones de la Amazonía colombiana, peruana, boliviana y brasileña. Dentro de este grupo también quedó agrupado un ejemplar de C. robustus muestreado en el estado brasileño Espíritu Santo. Relacionado con ese grupo también apareció un grupo de ejemplares muestreados en el sur de Brasil (Mato Grosso) y Paraguay (C. a. paraguayanus $=c a y)$. Más divergentes, y a los que se puede considerar especies diferenciadas de $C$. apella como han sugerido otros autores (Rylands et al. 1997, Groves 2001), aparecieron C. xanthosternos y C. nigritus. 


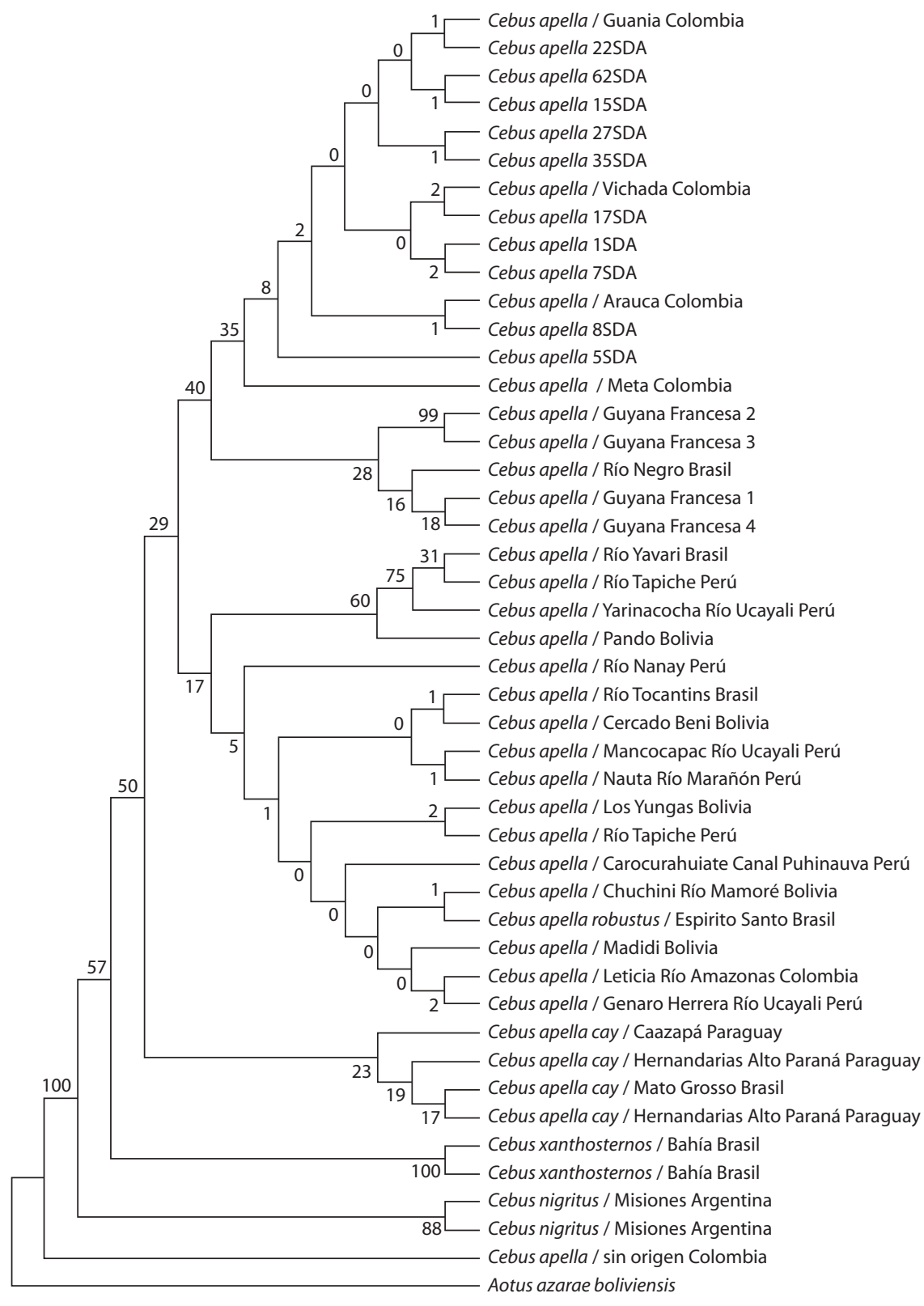

Fig. 5. Árbol de máxima parsimonia con secuencias de 590 pb del gen mtCOII aplicado al primate neotropical, Cebus apella.

Fig. 5. Maximum parsimony tree with sequences of $590 \mathrm{bp}$ at the mtCOII gene applied to the neotropical primate, Cebus apella. 


\section{DISCUSIÓN}

Saguinus leucopus: La asociación de ejemplares de Saguinus leucopus en los diferentes clados es independiente del lugar geográfico de procedencia de las muestras, por lo que es posible concluir que, para esta especie, se presenta un sólo acervo genético que se localiza a lo largo de todo su rango de distribución, por lo que, la liberación de ejemplares en cualquier lugar del rango geográfico propio, no tendría efectos genéticos negativos "a priori" en las poblaciones receptoras. Se observó, también, cómo los haplotipos de $S$. oedipus (los cuatro ejemplares procedentes de la SDA) se encontraron entremezclados con los haplotipos de S. leucopus. Esto pone en evidencia que ambas especies están altamente relacionadas desde una perspectiva filogenética y algunos autores (como Hernández-Camacho \& Cooper 1976) las consideraron subespecies. Por el contrario, S. fuscicollis y, especialmente, $S$. labiatus están filogenéticamente más alejados de S. leucopus.

S. leucopus se localiza principalmente en el noreste de Antioquia, en los municipios de Cáceres y Valdivia, en el valle medio del río Nechí, el sur de Bolívar (incluyendo la isla de Mompós) y la orilla occidental del Río Magdalena en el departamento de Caldas y en el norte de Tolima (hasta las cercanías de Mariquita) (Defler 2003, Morales-Jiménez et al. 2004). Los ejemplares aquí analizados procedentes del medio natural fueron muestreados en una zona del Tolima, en otra zona de Caldas y diversas áreas de Antioquia, más algunos ejemplares procedentes del Departamento de Bolívar. Los ejemplares decomisados no formaron agrupaciones consistentes con áreas geográficas determinadas con lo que no se apreció ninguna objeción para liberarlos en cualquier zona con las condiciones ecológicas pertinentes y dentro del rango de distribución de la especie. Sin embargo, cabe resaltar que Leguizamón et al. (2006) y Ruiz-García et al. (2010f) reportaron la capacidad de discriminar dos acervos genéticos diferentes en el rango de distribución endémico en Colombia de esta especie, mediante nueve marcadores microsatélites (STRPs), uno correspondiente al sur de la distribución (Departamento del Tolima) y otro más al norte en el Departamento de Antioquia. Es posible que los microsatélites, al ser extremadamente polimórficos, hayan sido más sutilmente afectados, que las secuencias mitocondriales, por procesos de deriva genética que hayan acaecido en esas poblaciones debido a la destrucción de hábitat, fijando diferentes alelos en cada uno de los dos acervos genéticos citados. Sin embargo, las secuencias mitocondriales pueden mostrar de una forma más precisa cómo fue el proceso de colonización del área donde esta especie existe y cómo, primariamente, no hubo ninguna barrera para el flujo génico entre las poblaciones originales, que fueron dispersándose por el rango de distribución geográfica alcanzado por la especie. Por lo tanto, parece claro que no existe ningún proceso sub-especiativo en el seno de S. leucopus. Igualmente, el ADN mitocondrial reconstruye únicamente la evolución de los linajes femeninos. Si existiera un flujo génico diferencial entre machos y hembras (con los machos presentando un flujo génico más reducido que las hembras), ese evento también ayudaría a explicar las diferencias encontradas entre marcadores nucleares (microsatélites) y el ADN mitocondrial.

Aotus sp.: Resultó evidente que de los 14 Aotus decomisados analizados, 11 procedieron de dos taxones de cercanía geográfica a Bogotá (griseimembra y brumbacki). Curiosamente, dos individuos decomisados quedaron agrupados con el grupo integrado por $A$. azarae azarae (norte de Argentina y Paraguay) y $A$. azarae boliviensis (Bolivia), cuando éstas no son especies que se encuentren en Colombia. Eso induce a pensar que pueden haber llegado a Colombia especimenes de Aotus, probablemente, procedentes de Argentina o Paraguay. Es probable que la utilización de ejemplares del género Aotus en laboratorios, dónde se investiga acerca de la malaria y otras enfermedades tropicales, haya potenciado el tráfico ilegal de otras especies de Aotus no presentes en Colombia (Ruiz-García et al. 2010a). En Colombia 
están presentes otros taxones de Aotus: A. lemurinus lemurinus (=hershkovitzi), en las montañas de las cordilleras Central y Oriental (siempre en altura); A. zonalis (A. lemurinus zonalis) en la zona chocoana alcanzando Panamá; posiblemente A. trivirgatus en el área de Maipurés (Departamento del Vichada) en la frontera de la Orinoquía entre Colombia y Venezuela, pudiéndose, eventualmente, dar una especie adicional para Colombia, A. jorgehernandezi en la zona del Quindío (Torres et al. 1998, Defler \& Bueno 2007). Futuros ejemplares de Aotus decomisados en Bogotá podrán ser asignados a cualquiera de los taxones presentes en Colombia, o Latinoamérica, ya que en nuestro laboratorio se han generado secuencias para todos los taxones de este género.

Cebus albifrons: Se observó que la mayor parte de C. albifrons decomisados en el año 2008 en Bogotá (10/14) proceden de la orilla derecha del río Magdalena atravesando los departamentos de Santander y norte de Santander hasta la región del Catatumbo. Esta es una especie que presenta una distribución muy fragmentada en Colombia. Hershkovitz (1949) determinó la existencia nueve subspecies de C. albifrons en Colombia, malitosus, cesarae, pleei, versicolor y leucocephalus en el norte del país, adustus y albifrons en los Llanos Orientales; en la Amazonía unicolor y yuracus. Estudios posteriores (Hernández-Camacho \& Cooper 1976, Defler \& Hernández-Camacho 2002) disminuyeron el número de subespecies para Colombia: cesarae, pleei, versicolor y leucocephalus que fueron asignados a una única subespecie, versicolor, mientras que adustus, albifrons y unicolor a la única subespecie, albifrons. Por el contrario, Ruiz-García et al. (2010e) mostraron a nivel molecular como la clasificación de Hershkovitz (1949) está sustentada (con la excepción de C. a. adustus) $\mathrm{y}$, por lo tanto, es importante considerar los diferentes acervos genéticos de la parte norte del país, y no liberar ejemplares de esta especie en cualquier lugar de la distribución geográfica de versicolor sensu Hernández-Camacho \& Cooper (1976). Igualmente importante tener en cuenta que en la Amazonia existen en simpatría dos o tres taxones de C. albifrons (grupos III, IV y V, siguiendo la nomenclatura de RuizGarcía et al. 2010e), lo cual dificultaría la liberación de $C$. albifrons en diversas zonas de la Amazonía peruana, colombiana y brasileña. Sin embargo, todas las muestras decomisadas en Bogotá parecen pertenecer a grupos del norte de Colombia, con la excepción de un ejemplar que no pudo ser asignado a ningún taxón de $C$. albifrons en Colombia.

Cebus capucinus: Diversos autores han considerado cuatro subespecies de C. capucinus (Rylands et al. 1997): C. c. capucinus, propia de la Colombia continental en la zona Pacífica y Caribe; C. c. curtus, en la isla de Gorgona en el Pacífico colombiano; $C$. $c$. imitator, en Panamá y Costa Rica; y C. c. limitaneus, en Nicaragua, Honduras y Belice (poblaciones de este taxa también están presentes en Guatemala; Ruiz-García, observ. pers.). Parece que en Colombia existen dos acervos genéticos definidos: uno que se extiende por el norte del Chocó, Sucre y Córdoba y ciertas zonas del Cauca y Valle del Cauca, y otro, que se extiende por Antioquia y diversas áreas del Magdalena y del Cauca. El primer acervo estaría más relacionado con el centroamericano detectado, que con el segundo acervo determinado en territorio colombiano. Por otra parte, no pareciera consolidarse la existencia de dos subespecies en Centroamérica. Las secuencias de dos ejemplares de Costa Rica fueron muy semejantes a la de un individuo muestreado cerca de Livingstone (Guatemala). Esta es una especie infrecuente en los decomisos de Bogotá, debido a la lejanía entre su rango de distribución y la capital colombiana.

Cebus apella: El análisis molecular con este taxón mostró básicamente que a Bogotá arriban ejemplares de los Llanos Orientales, y no del Amazonas, y que esta población está altamente relacionada con el holotipo de la especie descrito por Linneo y restringido por Humboldt y Hershkovitz (1958) a la Guyana francesa, C. a. apella. Groves (2001) definió 
como C. a. fatuellus la forma de apella descrita en la parte superior de la cuenca del Magdalena por Tate y que él visualizó en el Departamento del Meta, en el río Guaviare. Por lo tanto, se podrían dividir en dos subespecies diferentes esas poblaciones de C. apella al norte del Río Amazonas, C. a. apella y C. a. fatuellus (esta última específica de Colombia). Igualmente, la afirmación de Hernández-Camacho \& Cooper (1976) por la cuál únicamente existiría un único acervo genético de $C$. apella en Colombia parece incorrecto. Claramente, existen dos acervos genéticos diferenciados en este país sudamericano. El ya comentado en los Llanos Orientales y norte de la Amazonía colombiana (Departamento del Guainía) y otro en el resto de la Amazonía colombiana que también se distribuye ampliamente por la Amazonía peruana, boliviana y brasileña. Este último lo designaremos tentativamente $C$. apella macrocephalus. No parece que los otros taxones atribuibles a C. apella en la Amazonía occidental (y en otras partes de Brasil) tengan razón de ser a la luz de las secuencias del gen mtCOII: ejemplares que geográfica y morfológicamente fueron clasificados "a priori" como C. a. maranonis, C. a. peruanus, C. a. pallidus (o C. libidinosus pallidus), C. a. juruanus (о C. libidinosus juruanus) $\mathrm{e}$, incluso, C. robustus fueron parte de este gran clado básicamente, pero no exclusivamente amazónico. Sin embargo, existen tres clados bien sustentados por el porcentaje de "bootstrap" y que pueden conformar tres taxones, relacionadas con $C$. apella, pero diferentes. Este sería el caso de $C$. cay (=C. a. paraguayanus) y que nosotros consideramos una subespecie más de $C$. apella porque sus distancias genéticas con respecto a C. a. macrocephalus son muy limitadas, C. xanthosternos (muestras procedentes del Centro de Primatología de Rio de Janeiro donadas por el Dr. A. Pissinati y procedentes del sudeste del estado brasileño de Bahía) y C. nigritus (muestras procedentes de la provincia de Misiones, nordeste de Argentina). La taxonomía y filogeografía de C. apella, y taxones relacionados, se discute en Rylands et al. (2005) y Ruiz-García \& Castillo (2010).
Por lo tanto, las secuencias del gen mtCOII mostraron un alto poder de determinación y asignación de los primates decomisados, en Bogotá, a diversos acervos genéticos, con una distribución geográfica específica para las especies de primates colombianas. De este modo, es posible utilizar esta herramienta molecular para asignar ejemplares, que permita la reintroducción, en las áreas geográficas originales, antes de ser ilegalmente extraídos de sus respectivos ambientes. El método es replicable y rápido, y ya se ha conformado en Colombia el primer banco de secuencias para ese fin.

Sin embargo, para poder proceder en ese sentido, se hace necesario analizar previamente una elevada cantidad de muestras con orígenes geográficos conocidos de taxones de esos géneros, a lo largo de la geografía colombiana y de otros puntos de Latinoamérica (especialmente Perú, Ecuador, Venezuela y Brasil), ya que existe un tráfico ilegal de fauna que implica varios países latinoamericanos.

\section{AGRADECIMIENTOS}

Agradecemos los recursos económicos obtenidos mediante el proyecto "Fortalecimiento del control y prevención del tráfico ilegal de fauna silvestre, especialmente de primates, a través de la determinación de zonas sometidas a extracción ilegal utilizando pruebas de genética molecular de poblaciones" financiado por la SDA y la Pontificia Universidad Javeriana. La financiación de los proyectos con genética de poblaciones y filogeografía molecular de delfines de río por parte de Colciencias (Proyecto 1203-09-11239; Geographical population structure and genetic diversity of two river dolphin species, Inia boliviensis and Inia geoffrensis, using molecular markers) y al Fondo para la Acción Ambiental (US-Aid) (120108E0102141; Structure and Genetic Conservation of river dolphins, Inia and Sotalia, in the Amazon and Orinoco basins) permitieron al primer autor conseguir miles de muestras de mamíferos amazónicos en Colombia, Perú, Ecuador, Bolivia y Brasil, muchas de ellas pertenecientes a los primates estudiados. Sin 
la ejecución de esos proyectos no se habrían podido conseguir buena parte de las muestras de primates que fueron comparadas con las de los primates decomisados por la SDA. Gracias a la Dra. Diana Álvarez, Pablo Escobar-Armel y Luisa Fernanda Mora-Castellanos por la invaluable ayuda en la obtención de muestras de primates con un origen geográfico preciso. Se agradece de forma especial al Ministerio de Medio Ambiente de Perú, a PRODUCE (Dirección Nacional de Extracción y Procesamiento Pesquero de Perú), al Consejo Nacional del Ambiente y al Instituto Nacional de Recursos Naturales (INRENA) por su ayuda en la obtención de los permisos de colecta en Perú. Igualmente agradecemos a la Dirección General de Biodiversidad y CITES de Bolivia por facilitar los permisos de recolección de muestras en ese país. Se agradece de forma enfática a las comunidades Ticuna, Yucuna, Yaguas, Witoto y Cocama en la Amazonía colombiana, a las comunidades Bora, Ocaina, Shipibo-Comibo, Capanahua, Angoteros, Orejón, Yaguas, Cocama, Kishuarana y Alama en la Amazonía peruana, a las comunidades Maruba, Matis, Mayoruna, Kanaimari, Kulina, Maku y Waimiri-Atroari en la Amazonía brasileña, y a las comunidades Sirionó, Canichana, Cayubaba y Chacobo en la Amazonía boliviana. Damos gracias por la ayuda, en forma de muestras, proporcionadas por Armando Castellanos (Fundación Zoobreviven) y Luís Albuja (Escuela Politécnica Nacional de Quito) desde el Ecuador, al Dr. Alcides Pissinatti del Centro de Primatología de Río de Janeiro (Brasil), quién nos hizo llegar dos muestras de Cebus xanthosternus, al Dr. Benoit de Thoysi, quién nos proporcionó cuatro muestras de Cebus apella apella de Guyana Francesa y a Hugo Gálvez (Iquitos, Perú), por proporcionar gran cantidad de muestras de Aotus, Saimiri, Saguinus y Cacajao. Agradecemos la ayuda prestada por Corantioquia, Corpoamazonía, Corpocaldas, Instituto Humboldt, URRAS, UNAU, WSPA, Natura, y Omacha (en Colombia), al Centro de Primatología de Iquitos (Perú) y muy especialmente a la Colección Boliviana de Fauna (Dra. Julieta Vargas), a WCS Bolivia (Dr. Robert
Wallace) y la Universidad de San Andrés (Dra. Volga Iñiguez) en La Paz (Bolivia).

\section{RESUMEN}

Los primates son uno de los grupos de mamíferos más decomisados por la autoridades ambientales (SDA) en Bogotá, Colombia. Un total de 133 primates fueron confiscados en Bogotá durante el año 2008 y mantenidos en las instalaciones de la SDA. De ellos, 115 fueron secuenciados para el gen mitocondrial citocromo oxidasa II (mtCOII) y en 112 ejemplares, las secuencias obtenidas fueron de alta calidad. Esas secuencias se compararon con las obtenidas para ejemplares muestreados directamente en campo por nuestro grupo de investigación y con origen geográfico conocido. De ese modo, se pudo determinar las áreas geográficas, en el territorio colombiano, donde pueden liberarse esos ejemplares después del tratamiento de rehabilitación oportuno. Los resultados principales para las cinco especies de primates fueron como siguen: 1- Para Saguinus leucopus, los animales analizados pueden ser liberados en cualquier área geográfica dentro del rango de distribución de la especie, ya que solo se detectó un acervo genético sin estructura espacial. 2- Para los 14 Aotus sp. secuenciados procedentes de la SDA, se determinó que: uno de ellos pertenecía a $A$. vociferans, propio de la Amazonía; siete ejemplares pertenecieron a A. griseimembra, propio del valle del Magdalena hasta la costa Caribe colombiana; cuatro ejemplares representaron a A. brumbac$k i$, de los Llanos Orientales de Colombia; y dos ejemplares se asociaron con A. azarae azarae del norte de Argentina y Paraguay, con lo cual se muestra que en Colombia se está recibiendo fauna ilegal procedente de otros países. 3- De los 14 Cebus albifrons secuenciados, dos pertenecieron al área geográfica de distribución de C. a. versicolor; uno al de C. a. pleei, 10 al de C. a. leucocephalus, y uno no pudo ser asignado ya que su secuencia mostraba gran divergencia respecto a los otros ejemplares secuenciados de esta especie. 4- Los dos Cebus capucinus secuenciados mostraron estar asociados a un acervo genético encontrado en el norte del Chocó, Sucre y Córdoba. 5- De 11 Cebus apella secuenciados, 10 mostraron pertenecer al acervo genético que se encuentra en los Llanos Orientales de Colombia y altamente relacionado a Cebus apella apella de la Guyana Francesa, aunque podrían representar un acervo propio de Colombia, C. a. fatuellus sensu Groves (2001). Un individuo no pudo ser relacionado con ningún grupo de los otros C. apella estudiados, ni con los taxones relacionados a la especie mencionada, pero, probablemente, con su propio estatus taxonómico (C. a. paraguayanus $=$ C. cay, C. xanthosternos, C. nigritus).

Palabras claves: genética de poblaciones, marcadores moleculares, primates, reubicación de fauna decomisada, Saguinus leucopus, Aotus sp., Cebus albifrons, Cebus capucinus, Cebus apella. 


\section{REFERENCIAS}

Adkins, R.M \& R.L. Honeycutt. 1994. Evolution of the primate cytochrome c oxidase subunit II gene. J. Mol. Evol. 38: 215-231.

Ascunce, M.S., E. Hasson \& M.D. Mudry. 2002. Description of the cytochrome c oxidase subunit II in some genera of New World monkeys (Primates, Platyrrhini). Genetica 114: 253-267.

Ascunce, M.S., E. Hasson \& M.D. Mudry. 2003. COII: a useful tool for inferring phylogenetic relationships among New World monkeys (Primates, Platyrrhini). Zoolog. Scripta 32: 397-406.

Ashley, M.V. \& T.A. Vaughn. 1995. Owl monkeys (Aotus) are highly divergent in mitocondrial cytochrome c oxidase (COII) sequences. Int. J. Primatol. 5: 793807.

Avise, J.C. \& R.M. Ball. 1990. Principles of genealogical concordance in species concepts and biological taxonomy, p 45-67. In D. Futuyma \& J. Antonovics (eds.). Oxford Surveys in Evolutionary Biology. Vol. 7. Oxford, Oxford, Inglatera.

Capaldi, R.A. 1990. Structure and function of cytochrome c oxidase. Ann. Rev. Biochem. 59: 569-596.

Collins, A.C. \& J.M. Dubach. 2000a. Phylogenetic relationships of spider monkeys (Ateles) based on mitochondrial DNA variation. Int. J. Primatol. 21: 381-420.

Collins, A.C. \& J.M. Dubach. 2000b. Biogeographic and ecological forces responsible for speciation in Ateles. Int. J. Primatol. 21: 421-444.

Cortes-Ortiz, L., E. Bermingham, C. Rico, E. RodriguezLuna, I. Sampaio, M. Ruiz-García. 2003. Molecular systematics and biogeography of the Neotropical monkey genus, Alouatta. Mol. Phylog. Evol. 26: 64-81.

Defler, T. 2003. Primates de Colombia. Conservación Internacional. Panamericana, Bogotá D.C., Colombia.

Defler, T.R. \& J.I. Hernández-Camacho. 2002. The true identity and characteristics of Simia albifrons Humboldt, 1812: Description of neotype. Neotrop. Primates $10: 1-16$.

Defler T. \& M.L. Bueno. 2007. Aotus diversity and the species problem. Primates Conserv. 22: 55-70.

Drummond, A.J. \& A. Rambaut. 2007. BEAST: Bayesian evolutionary analysis by sampling trees. BMC Evol. Biol. 7: 214

Figueiredo, W.B., N.M. Carvalho-Filho, H. Schneider \& I. Sampaio. 1998. Mitochondrial DNA sequences and the taxonomic status of Alouatta seniculus populations in Northeastern Amazonia. Neotrop. Primates 6: 73-77.

Girman, D.J., P.W. Kat, G. Mills. 1995. A genetic and morphological analysis of the African wild dog (Lycaon pictus). J. Hered. 86: 334-342.

Groves, C.P. 2001. Primate Taxonomy. Smithsonian Institution, Washington D.C., EEUU.

Hershkovitz, P. 1949. Mammals of northern Colombia. Preliminary report $n^{\circ} 4$ : Monkeys (Primates), with taxonomic revisions of some forms. Proc. U.S. Nat. Mus. 98: 323-427.

Hershkovitz, P. 1958. Type localities and nomenclature of some American Primates, with remarks on secondary homonyms. Proc. Biol. Soc. Wash. 71: 53-56.

Hernández-Camacho J. \& R.W. Cooper. 1976. The nonhuman primates of Colombia, p. 35-69. In R.W. Jr. Thorington \& P.G. Heltne (eds.). Neotropical primates, field studies and conservation.

Kimura M. 1980. A simple method for estimating evolutionary rate of base substitutions through comparative studies of nucleotide sequences. J. Mol. Evol. 16:111-120.

Leguizamon, N., M. Ruiz-García, M.I. Castillo. 2006. Aplicaciones de los análisis genético poblacionales a partir de genotipos multilocus y metodologías basadas en modelos bayesianos para la conservación de la especie Saguinus leucopus. Conservación ex-situ 2: $17-28$.

Lynch, M. 1991. The genetic interpretation of inbreeding and outbreeding depresision. Evolution 45: 622-629.

Morales-Jimenez, A., F. Sánchez, K. Poveda \& A. Cadena, A. 2004. Mamíferos terrestres y voladores de Colombia. Guía de campo. Instituto de Ciencias Naturales, Universidad Nacional de Colombia, Bogotá, Colombia. $248 \mathrm{p}$.

Nei, M.S. Kumar. 2000. Molecular Evolution and Phylogenetics. Oxford, Oxford, Inglaterra.

Nieves, M., M.S. Ascunce, M.I. Rahn \& M.D. Mudry. 2005. Phylogenetic relationships among some Ateles species: the use of chromosomic and molecular characters. Primates 46: 155-164.

Plautz, H.L., E.C. Goncalves, S.F. Ferrari, M.P.C. Schneider \& A. Silva. 2009. Evolutionary inferences on the diversity of the genus Aotus (Platyrrhini, Cebidae) from mitochondrial cytochrome c oxidase subunit II gene sequences. Mol. Phylog. Evol. 51: 382-387. 
Ramharack R. \& R.G. Deeley. 1987. Structure and evolution of primary cytochrome c oxidase 1163 subunit II gene. J. Biol. Chem. 262: 14015-14021.

Ronquist, F. \& J.P. Huelsenbeck. 2003. MrBayes 3: Bayesian phylogenetic inference under mixed models. Bioinformatics 19: 1572-1574.

Ruiz-García, M. \& M.I. Castillo. 2010. Taxonomy considerations and molecular phylogeography of Cebus apella and related taxa with the COII mitochondrial gene. Primates (en prensa).

Ruiz-García, M. \& M. Pinedo. 2010a. Molecular Systematics and Phylogeography of the genus Lagothrix (Atelidae, Primates) by means of mitochondrial COII gene. Folia Primatologica (en prensa).

Ruiz-García, M. \& M. Pinedo. 2010b. A global perspective of the evolutionary history and phylogeny of the genus Lagotricha (Atelidae, Primates) by means of mitochondrial DNA sequences with special emphasis in the historical demographic trajectories of diverse Lagothrix taxa, pp. 197-216. In M. Ruiz-García (ed.). Molecular population genetics, phylogeny and evolutionary biology of neotropical primates. Research Signpost, Transworld Research Network, Kerala, India.

Ruiz-García, M. \& M. Pinedo. 2010c. Lagothrix and Oreonax: A molecular perspective of their differences and their respective evolutionary trajectories. Mol. Phylog. Evol. (en prensa).

Ruiz-García, M., C. Vásquez, E. Camargo, N. Leguizamon, L.F. Castellanos-Mora, A. Vallejo \& J. Shostell, D. Alvarez. 2010a. Molecular phylogeny of the Aotus genus (Cebidae, Primates) and its illegal traffic in Colombia. Int. J. Prim. (en prensa).

Ruiz-García, M., P. Escobar-Armel, F. Nassar \& D. Alvarez. 2010b. Coalescence, bayesian phylogenetics and genetic structure of the Alouatta seniculus populations in Colombia and Perú by means of DNA microsatellites and mtDNA. J. Evol. Biol. (en prensa).

Ruiz-García, M., N. Lichilin, G. Gutierrez-Espeleta, B. Thoysi \& P. Escobar-Armel. 2010c. A complete molecular phylogeny of the Ateles genus by means of mitocondrial genes and DNA microsatellites. Mol. Phylog. Evol. (en prensa).

Ruiz-García, M., M.I. Castillo, G. Gutierrez-Espeleta \& A. Ledezma. 2010d. Phylogeography of Cebus capucinus (Cebidae, Primates) in Colombia and Costa Rica by means of mtCOII gene sequences. Am. J. Prim. (en prensa).

Ruiz-García, M., M.I. Castillo, C. Vásquez, K. Rodriguez, J. Shostell, \& N. Leguizamon. 2010e. Molecular Phylogenetics and Phylogeography of the
White-fronted capuchin (Cebus albifrons; Cebidae, Primates) by means of mtCOII gene sequences. Mol. Phylog. Evol. (en prensa).

Ruiz-García, M., P. Escobar-Armel, N. Leguizamon \& P. Manzur. 2010f. Genetic characterization and structure of the Colombian endemic Primate, Saguinus leocopus, by means of DNA microsatellites and mtCOII sequences. Int. J. Prim. (en prensa).

Rylands, A.B., E. Rodriguez-Luna \& L. Cortés-Ortiz. 1997. Neotropical Primate Conservation-The species and the IUCN/SSC Primate Specialist Group Network. Primate Conserv. 17: 46-69.

Rylands, A.B., M.C.M. Kierulff \& R.A. Mittermeier. 2005. Notes on the taxonomy and distribution of the tufted capuchin monkeys (Cebus, Cebidae) of South America. Lundiana 6: 97-110.

Sambrook, J., E.F. Fritsch, \& T. Maniatis. 1989. Molecular cloning: A laboratory manual. Cold Spring Harbor Laboratory, Nueva York, EEUU.

Saitou, N. \& M. Nei 1987. The neighbor-joining method: a new method for reconstructing phylogenetic trees. Mol. Biol. Evol. 4: 405-425.

Sena, L., M. Vallinoto, I. Sampaio, H. Scheneider, S.F. Ferrari \& M.P.C. Scheneider. 2002. Mitochondrial COII gene sequences provide new insights into the phylogeny of marmosets species groups (Callitrichidae, Primates). Folia Primatologica 73: 240-251.

Sneath, P.H.A. \& R.R. Sokal. 1973. Numerical Taxonomy. Freeman, San Francisco, EEUU.

Tamura, K. 1992 Estimation of the number of nucleotide substitutions when there are strong transition-transversion and $\mathrm{G}+\mathrm{C}$ content biases. Mol. Biol. Evol. 9: 678-687.

Tamura, K., M. Nei \& S. Kumar. 2004. Prospects for inferring very large phylogenies by using the neighborjoining method. Proc. Nat. Acad. Sci. USA. 101: 11030-11035.

Templeton, A.R. 1986. Coadaption and outbreeding depression, p. 105-116. In M.E. Soulé (ed.). Conservation Biology. The science of scarcity and diversity. Sinauer, Sunderland, Massachusetts, EEUU.

Templeton, A.R. 1989. The meaning of species and speciation: a genetic perspective, p. 3-27. In D. Otte, J.A. Endler (eds.). Speciation and its consequences. Sinauer, Sunderland, Massachusetts, EEUU.

Torres, O.M., S. Enciso, F. Ruiz, E. Silva, \& I. Yunis. 1998. Chromosome diversity of the genus Aotus from Colombia. Am. J. Prim. 44: 255-275. 